\title{
Lessons LeARned FROM REINFORCING EPIDEMIOLOGIC Surveillance During the 2017 Ebola Outbreak in the Likati District, Democratic Republic of the Congo
}

Jennifer J. Hemingway-Foday, Bonaventure Fuamba Ngoyi, Christian Tunda, Kristen B. Stolka, Kathryn E. L. Grimes, Léopold Lubula, Mathias Mossoko, Benoit Ilunga Kebela, Linda M. Brown, and Pia D. M. MacDonald

On May 12, 2017, the Democratic Republic of Congo (DRC) publicly declared an outbreak of Ebola virus disease (EVD) in the Likati District of the Bas-Uéle Province, 46 days after the index case became symptomatic. The delayed EVD case detection and reporting highlights the importance of establishing real-time surveillance, consistent with the Global Health Security Agenda. We describe lessons learned from implementing improved EVD case detection and reporting strategies at the outbreak epicenter and make recommendations for future response efforts. The strategies included daily coordination meetings to enhance effective and efficient outbreak response activities, assessment and adaptation of case definitions and reporting tools, establishment of a community alert system using context-appropriate technology, training facility and community health workers on adapted case definitions and reporting procedures, development of context-specific plans for outbreak data management, and strengthened operational support for communications and information-sharing networks. Post-outbreak, surveillance officials should preemptively plan for the next outbreak by developing emergency response plans, evaluating the case definitions and reporting tools used, retraining on revised case definitions, and developing responsive strategies for overcoming telecommunications and technology challenges. The ongoing EVD outbreak in the North Kivu and Ituri provinces of DRC, currently the second largest EVD outbreak in history, demonstrates that documentation of successful context-specific strategies and tools are needed to combat the next outbreak. The lessons learned from the rapid containment of the EVD outbreak in Likati can be applied to the DRC and other rural low-resource settings to ensure readiness for future zoonotic disease outbreaks.

Keywords: Epidemic management/response, Infectious diseases, Public health preparedness/response, Surveillance, Ebola virus disease, Democratic Republic of Congo

Jennifer J. Hemingway-Foday, MPH, MSW, is a Research Epidemiologist, and Kristen B. Stolka, MPH, and Kathryn E. L. Grimes, MPH, are Research Public Health Analysts; all at RTI International, Research Triangle Park, NC. Bonaventure Fuamba Ngoyi, MD, is a Field Epidemiologist, and Christian Tunda, ME, is an Information Communication Technology Specialist, working as a consultant; both at RTI International, Kinshasa, Democratic Republic of Congo. Léopold Lubula, MD, MPH, is Surveillance Manager; Mathias Mossoko, MSc, is Data Manager; and Benoit Ilunga Kebela, MD, is Director; all at the Ministry of Public Health, Kinshasa, Democratic Republic of Congo. Linda M. Brown, PhD, is Senior Research Epidemiologist, RTI International, Rockville, MD. Pia D. M. MacDonald, PhD, is Senior Director/Senior Epidemiologist, RTI International, Berkeley, CA. 
$\mathrm{O}$ N MaY 12, 2017, THE Ministry of Health of the Democratic Republic of Congo (DRC) publicly declared an Ebola virus disease (EVD) outbreak in the Likati District of the Bas Uéle Province in northern DRC, the country's eighth EVD outbreak since $1976 .^{1,2}$ In 2018, DRC recorded 2 additional EVD outbreaks in the provinces of Equateur (May-July 2018) and then North Kivu (August 2018-present $\left.{ }^{*}\right){ }^{3}$ the latter is still ongoing. ${ }^{4}$ The DRC health authorities are globally recognized for their expertise in outbreak response, as evidenced by the rapid containment of 9 EVD outbreaks, more than any other country. ${ }^{5,6}$ Nonetheless, the context of the Likati outbreak presented unique challenges that contributed to the delayed detection and reporting of the index case, including acute infrastructural deficiencies, an under-resourced health system, and geographic isolation from the capital city of Kinshasa, located 869 miles away (Figure 1). ${ }^{2,7,8}$ Subsequent investigation showed that the public declaration came 46 days after the index case became symptomatic and 19 days after the first patient (victim 2) reported to a health center with Ebola-like symptoms (Figure 1). By the official outbreak end on July 2, 2017, a total of 8 cases had been identified, with 4 deaths, for a case fatality rate of $50 \%$. Among the 8 cases, 2 were confirmed by polymerase chain reaction, 3 were confirmed by serology, and 3 were classified as probable, based on epidemiologic and clinical evidence.

The occurrence of 3 EVD outbreaks in less than 18 months points to an urgent need for proven strategies that can be adapted to future outbreaks in similar settings and leveraged for preemptive outbreak response. The Global Health Security Agenda provides a framework for strengthening both global and individual nations' capacity to prevent, detect, and respond to infectious disease threats. This multilateral and multisectoral agenda focuses efforts for countries to achieve compliance with the International Health Regulations (IHR), an agreement among all World Health Organization (WHO) member states. The IHR provide a common understanding of global expectations to mitigate potential public health threats. ${ }^{9,10}$ A systematic review of lessons learned from implementation of IHR core capacities found very little documentation of applicable lessons for Africa and none in the DRC. ${ }^{11}$

In response to this knowledge gap, we draw from our experience supporting the Likati EVD outbreak response to describe the specific surveillance and investigation strategies that contributed to rapidly containing the outbreak within 51 days of the public declaration. ${ }^{2}$ To meet the growing need for proactive plans to address emerging infectious disease threats, ${ }^{12,13}$ we document lessons learned and practical

*The North Kivu EVD outbreak began on August 1, 2018, and spread to the Ituri Province, where the first case was confirmed on August 13, 2018. As of September 24, 2019, the outbreak is ongoing, with 3,168 cases $(3,057$ confirmed and 111 probable) and 2,118 deaths reported. recommendations to help policymakers and first responders prepare for future zoonotic disease outbreaks in the DRC and similar resource-limited rural settings. Further, we aim to advance the goals of the Global Health Security Agenda by describing how these recommendations can prevent avoidable epidemics, detect threats early, and enable a rapid and effective response to infectious disease outbreaks.

\section{Materials and Methods}

\section{Background, Location, and Population}

The DRC is an epicenter for emerging zoonotic diseases and is considered one of the most vulnerable countries in the world for disease outbreak. ${ }^{14}$ Its tropical ecosystem is favorable to zoonotic disease development, with welldocumented emergence and reemergence of infectious disease pathogens. ${ }^{15-20}$ Many people rely on bushmeat as a source of food and income, contributing to a high risk of zoonotic spillover by putting humans in direct contact with wildlife, the main reservoir for emerging infectious diseases such as EVD, other viral hemorrhagic fevers, and monkeypox. ${ }^{15-17,20}$ Bushmeat was identified as the source of the Likati outbreak, with evidence that the index case was infected in a spillover event from contact with a carcass from a wild boar or nonhuman primate. ${ }^{2}$

The Likati district is heavily forested and largely rural, with a population of 70,858 and 6 inhabitants per square kilometer. The economy is based primarily on agriculture, fishing, and hunting, resulting in a highly mobile population, which increases risk of exposure to zoonotic threats and presents challenges for breaking chains of transmission. Health activities in the Likati district are managed by ministry of health staff at the district health office in the town of Likati, with additional oversight and support from the provincial health office in the provincial capital of Buta, approximately 100 miles away. Health services are provided at the general reference hospital in the town of Likati and 11 health centers, each with a distinct geographical catchment zone called a "health area." The Likati district lacks essential health infrastructure, with many people seeking care outside of the formal health structure. At the outbreak onset, the ministry of health reported that $50 \%$ of the population had health coverage and $60 \%$ could access the minimum package of public health services. At the health-center level, there were no health workers with post-baccalaureate education, and tools and equipment were insufficient for primary care provision and disease surveillance. ${ }^{7}$ These common infrastructure deficiencies, identified in previous EVD outbreaks, ${ }^{13}$ likely contribute to delays in detecting and reporting unusual health events. 


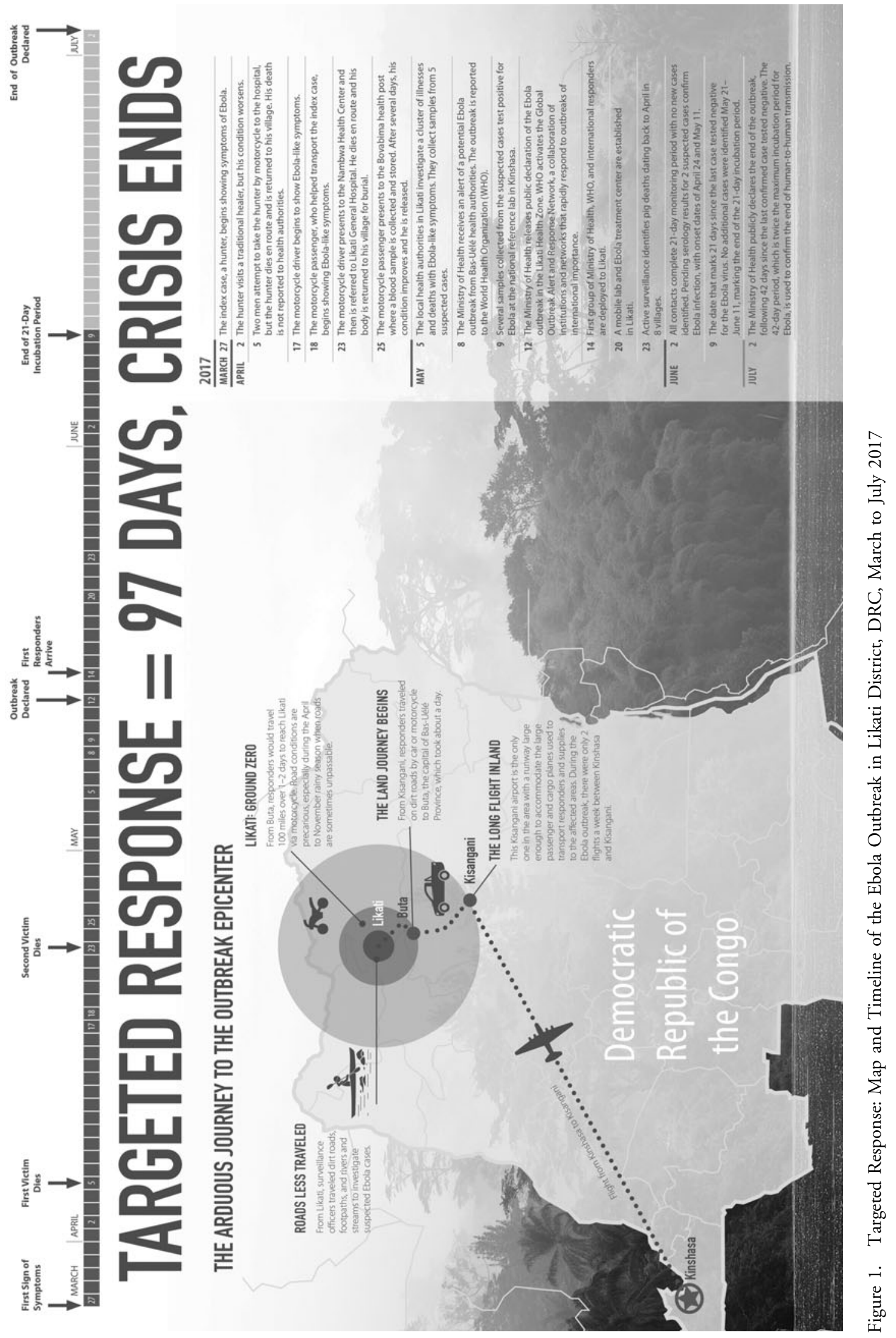




\section{Outbreak Response}

Within 48 hours of the outbreak declaration, the DRC government mobilized a team of experts and enacted a comprehensive response plan to define the critical activities, coordination structure, and required resources to rapidly and effectively contain the outbreak. ${ }^{8}$ The National Coordination Committee, based in Kinshasa, managed central response activities and provided support to the rapid response teams in Likati. Response activities were organized into 7 pillars: (1) surveillance and investigation, (2) medical management, (3) water/hygiene, (4) laboratory and research, (5) psychosocial support, (6) communication and social mobilization, and (7) logistics. Rapid response teams, composed of more than 30 experts from government and international agencies, were assembled for each response pillar and deployed to the epicenter to implement targeted activities. Daily coordination meetings were held in Kinshasa and Likati to monitor and adapt to the outbreak's evolving needs.

The surveillance team was led by the Ministry of Health's Division of Disease Control (Direction de Lutte contre la Maladie, or DLM), with support from field epidemiologists and information and communication technology specialists from RTI International, Médecins Sans Frontières, and WHO. Primary tasks included: (1) identifying the outbreak origin and chain of transmission; (2) collaborating with local health workers to detect and actively investigate reported cases and implement procedures for contact tracing and monitoring; (3) managing case, contact, and alert data; and (4) compiling and disseminating daily situation reports. We provide lessons learned during the support of these surveillance activities, drawing from the collection and analysis of outbreak surveillance data, direct observation, development of training materials, implementation of procedures for case detection and contact tracing, and documentation of the epidemiologic investigation.

\section{Surveillance Methods}

During the outbreak, the surveillance team investigated a total of 106 suspected cases and 583 contacts to trace the chain of transmission and identify the outbreak origin. They visited remote villages throughout the district to interview cases, contacts, health workers, and community members; review health records; investigate unexplained deaths and illness in humans and animals; and look for evidence of animal-to-human transmission.

Suspected cases were detected through active surveillance at health facilities and in the community, contact tracing activities, community-initiated alerts, and reports from other pillars. To support active case finding, facility-based health workers were trained on the outbreak-specific definitions for suspected, probable, and confirmed cases. When a suspected case was identified, a surveillance team member traveled to the reported location and, together with the local health worker, completed the case notification form and collected specimens for laboratory diagnosis. This provided epidemiologic and clinical data to assess and classify each case as suspected, probable, confirmed, or noncase, according to the outbreak-specific case definitions. By directly engaging health workers in case investigation activities, the surveillance team reinforced local capacity to document, manage, and report suspected cases in line with ministry of health surveillance guidelines.

To reinforce case ascertainment, the surveillance team also established a community alert system, which was publicized during community awareness campaigns and investigative activities (Figure 2). Alerts were investigated within 24 hours of receipt, classified as a suspected or noncase, and documented on the appropriate reporting form.

Community health workers supported case finding and contact monitoring activities. To improve detection of suspected cases by community health workers, a community case definition was developed by broadening the standard EVD case definition to include: (1) any person with sudden onset of fever, OR (2) any person with bleeding, bloody diarrhea, or blood in urine, OR (3) any sudden death. The purpose of the broadened case definition was to facilitate ascertainment of all illnesses or deaths potentially attributable to EVD for further investigation.

The surveillance team used participatory methods to train 98 community health workers on the community case definition, EVD signs and symptoms, case reporting procedures, and contact monitoring procedures. All contacts were monitored by community health workers for 21 days, using a standardized contact tracing form. A member of the surveillance team also visited the contact during the monitoring period to capture geolocation using an Androidbased application. At each health center, the head nurse was responsible for daily reports by phone to the response headquarters on the number of contacts being monitored and exiting 21-day follow-up. If EVD signs or symptoms were reported during contact monitoring, the head nurse immediately notified the surveillance team by phone so that an active case investigation could be initiated.

All case and alert data were collected on paper forms and sent to the Likati response headquarters for centralized data entry, with essential information sent by text message or reported verbally by phone while the paper forms were en route. For contacts, only paper records from the first contact interview were sent to the Likati response headquarters for centralized data entry; data for the remaining follow-up period (eg, temperature tracking) were maintained only on paper due to limited data entry personnel. Data were managed in Excel and the viral hemorrhagic fever case management system, an open-source software tool developed by the Centers for Disease Control and Prevention (CDC) to manage case and contact data during outbreaks. $^{21}$ The surveillance team compiled all case, alert, and contact data and produced a daily situation report, which was subsequently distributed to the national coordination committee and primary response partners. Moreover, the report was reviewed at the daily coordination meetings to 


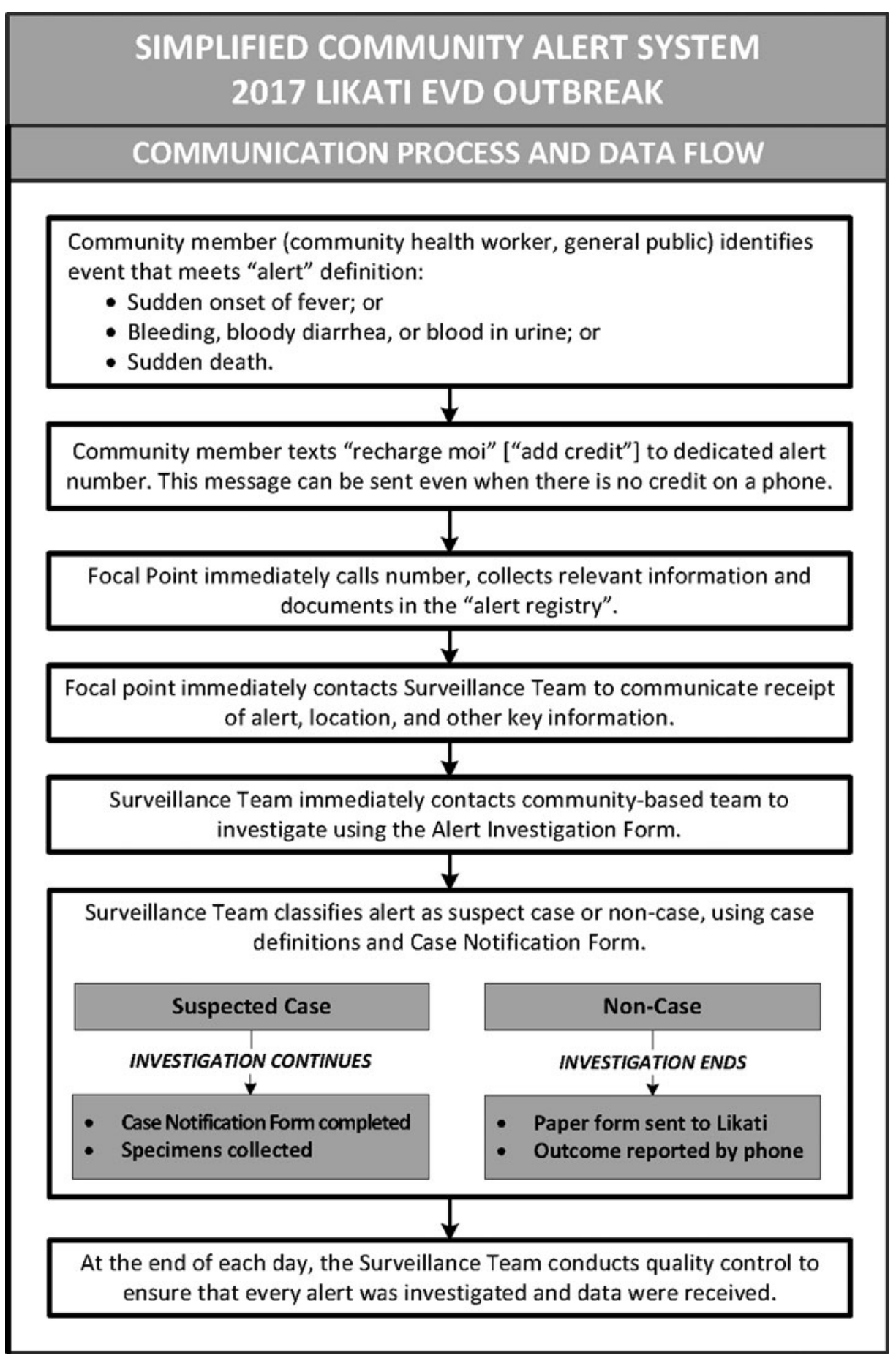

Figure 2. Communication Process and Data Flow for the Community Alert System Used During the Ebola Outbreak in Likati District, DRC, March to July 2017

monitor progress, evaluate effectiveness, identify problems, plan or modify activities, allocate resources or staff, and identify epidemiologic trends.

The surveillance team conducted additional investigative activities to determine the origin of the outbreak, identify the index case, and trace the chain of transmission. The epidemiologic investigation included analysis of surveil- lance data (eg, the case notification forms, case line listings, and contact registers), as well as interviews with surviving EVD cases, relatives of deceased cases, contacts, health workers, traditional healers, and community members in the areas where cases were identified.

The findings of the epidemiologic investigation suggest that all confirmed and probable cases originated from a 
Table 1. Lessons Learned and Practical Recommendations from the Ebola Outbreak in Likati District, DRC, May to June 2017

\begin{tabular}{|c|c|}
\hline Lesson Learned & Practical Recommendations \\
\hline \multicolumn{2}{|r|}{ During Outbreak } \\
\hline \multirow[t]{12}{*}{$\begin{array}{l}\text { Assess and adapt case } \\
\text { definitions and reporting } \\
\text { tools to outbreak context }\end{array}$} & $\begin{array}{l}\text { At the initiation of response activities, inventory and assess existing Ebola virus disease (EVD) } \\
\text { surveillance guidelines, case definitions, and reporting tools; then adapt to the outbreak } \\
\text { context: }\end{array}$ \\
\hline & - Case definitions: \\
\hline & $\begin{array}{l}\text { Broaden the community case definition to improve ascertainment of all illnesses or } \\
\text { deaths that are potentially attributable to EVD; }\end{array}$ \\
\hline & $\begin{array}{l}\text { Develop standard definitions for alerts so that they can be properly documented and } \\
\text { investigated, and ensure that the definition is widely disseminated to facility- and } \\
\text { community-based health workers, as well as response teams in other pillars; and }\end{array}$ \\
\hline & $\begin{array}{l}\text { Develop a standard definition for probable, confirmed, or non-case and detailed criteria } \\
\text { for health workers and surveillance team members to assess and assign all suspected cases } \\
\text { into the appropriate classification. }\end{array}$ \\
\hline & - Reporting tools: \\
\hline & $\begin{array}{l}\text { Revise existing reporting tools to facilitate more complete and accurate data by } \\
\text { enhancing standardized documentation of case identification, investigation, contacts, } \\
\text { clinical management, and laboratory diagnosis; }\end{array}$ \\
\hline & $\circ$ Create supplemental reporting tools, such as alert registers and investigation forms; and \\
\hline & $\begin{array}{l}\text { If supportive technology is available, implement tablet- or phone-based applications to } \\
\text { collect, transfer, and manage case data to improve the timeliness of case reporting and } \\
\text { reduce burden for case management. }\end{array}$ \\
\hline & - Surveillance guidelines: \\
\hline & $\begin{array}{l}\text { Provide supplemental guidance on roles and responsibilities at each level of the health } \\
\text { pyramid and clear lines of reporting; and }\end{array}$ \\
\hline & $\begin{array}{l}\text { Integrate supplemental guidelines and standard procedures for investigating and } \\
\text { documenting community alerts during the outbreak. }\end{array}$ \\
\hline \multirow{7}{*}{$\begin{array}{l}\text { Rapidly deploy a community } \\
\text { alert system using context- } \\
\text { appropriate technology }\end{array}$} & $\begin{array}{l}\text { - Establish a mechanism for community-initiated alerts. In limited-resource settings, the system } \\
\text { must be simple, low-cost, and easily accessible to community members: }\end{array}$ \\
\hline & O Ensure calls or texts to the alert system can be made at no cost to the individual reporter; \\
\hline & $\begin{array}{l}\text { Select focal point(s) to receive alerts on a dedicated mobile phone(s) and guidelines for } \\
\text { communicating alerts to the surveillance team; }\end{array}$ \\
\hline & $\circ$ Create an action plan to ensure follow-up investigation of all alerts within 24 hours; \\
\hline & $\circ$ Create supplemental documentation for tracking reported alerts; and \\
\hline & $\begin{array}{l}\text { - Increase uptake by widely disseminating information about the alert system in the } \\
\text { community, including identification of high-traffic public spaces, to post the contact number } \\
\text { for reporting alerts; and }\end{array}$ \\
\hline & $\begin{array}{l}\text { - Create efficiencies by integrating publicity of the alert system into existing community } \\
\text { awareness activities (eg, radio announcements, community sensitization, posters, etc), as well } \\
\text { as routine activities at local health facilities. }\end{array}$ \\
\hline \multirow[t]{4}{*}{$\begin{array}{l}\text { Build local capacity for case } \\
\text { detection and reporting }\end{array}$} & $\begin{array}{l}\text { At the community level, provide participatory training and supportive supervision to } \\
\text { community health workers by reinforcing: }\end{array}$ \\
\hline & 1) Knowledge of EVD signs and symptoms; \\
\hline & $\begin{array}{l}\text { 2) Comprehension and application of outbreak definitions relevant to community health } \\
\text { worker roles/responsibilities (community case definition, alert, contact); }\end{array}$ \\
\hline & $\begin{array}{l}\text { 3) Procedures for reporting alerts, suspected cases, and other unexplained illness or deaths in } \\
\text { the community; }\end{array}$ \\
\hline
\end{tabular}

(continued) 
Table 1. (Continued)

\begin{tabular}{|c|c|}
\hline Lesson Learned & Practical Recommendations \\
\hline & 4) Procedures for tracing and monitoring contacts; and \\
\hline & $\begin{array}{l}\text { 5) Best practices for infection prevention and control to protect against disease exposure } \\
\text { during direct interactions with suspected cases and contacts. }\end{array}$ \\
\hline & $\begin{array}{l}\text { At the district and provincial levels, provide on-the-job training and supportive supervision to } \\
\text { health workers at facilities and health offices by reinforcing: }\end{array}$ \\
\hline & 1) Knowledge of EVD signs and symptoms; \\
\hline & $\begin{array}{l}\text { 2) Comprehension and application of outbreak definitions (community case definition, } \\
\text { definition/criteria for suspected, probable, and confirmed cases, alert, contact); }\end{array}$ \\
\hline & $\begin{array}{l}\text { 3) Procedures for reporting and investigating alerts, suspected cases, and unexplained illnesses } \\
\text { or deaths; and }\end{array}$ \\
\hline & $\begin{array}{l}\text { 4) Timely notification of suspected cases or unexplained illnesses or deaths to higher-level } \\
\text { health authorities using standardized reporting tools. }\end{array}$ \\
\hline \multirow[t]{4}{*}{$\begin{array}{l}\text { Develop a context-specific plan } \\
\text { for outbreak data collection, } \\
\text { management, and use }\end{array}$} & $\begin{array}{l}\text { - Conduct a rapid assessment of existing surveillance data management systems and processes to } \\
\text { inform plans for supplemental resources and adaptive data management procedures required } \\
\text { for the local outbreak response, including: }\end{array}$ \\
\hline & $\begin{array}{l}\text { Suspected case and alert data: (1) Data collection, transmission, and management of case } \\
\text { data from the point of identification until final classification, including integration of } \\
\text { data from investigation, laboratory, and clinical care activities; (2) data validation; (3) } \\
\text { final case classification. }\end{array}$ \\
\hline & $\begin{array}{l}\text { Contact data: (1) Data collection, transmission, and management of contact tracing and } \\
\text { 21-day contact monitoring data; (2) daily communication between the surveillance team } \\
\text { and local contact tracers to initiate daily contact monitoring for newly identified } \\
\text { contacts and to report essential information collected during daily contact monitoring } \\
\text { activities; (3) immediate reporting of EVD symptoms identified during daily contact } \\
\text { monitoring to initiate active case investigation; (4) documentation of geolocation data } \\
\text { that is not reliant on technology and is well-integrated with contact tracing databases. }\end{array}$ \\
\hline & $\begin{array}{l}\text { All data: (1) Timely and accurate reporting from the response coordination teams at the } \\
\text { outbreak epicenter to the central response coordination committee; (2) feedback } \\
\text { mechanisms from the central response coordination committee to the outbreak } \\
\text { coordination teams and from the outbreak coordination teams to local health workers; } \\
\text { (3) ongoing integration of outbreak data into daily situation reports; (4) daily } \\
\text { dissemination of situation reports at the epicenter and national level to assess and adapt } \\
\text { response activities to the evolving outbreak situation. }\end{array}$ \\
\hline \multirow{5}{*}{$\begin{array}{l}\text { Strengthen operational support } \\
\text { for essential communication } \\
\text { and information-sharing } \\
\text { networks }\end{array}$} & $\begin{array}{l}\text { - Integrate information and communication technology (ICT) specialists into the surveillance } \\
\text { response team at the time of initial deployment to: }\end{array}$ \\
\hline & $\begin{array}{l}\text { Rapidly assess the existing ICT infrastructure and pinpoint resources that can be } \\
\text { leveraged or re-directed for essential communication and information-sharing during } \\
\text { the outbreak; }\end{array}$ \\
\hline & $\begin{array}{l}\text { Identify ICT strategies and supplemental equipment for addressing common constraints } \\
\text { in low-resource settings (eg, lack of cellular network coverage, inconsistent power } \\
\text { supply, disruptions in connectivity, etc); }\end{array}$ \\
\hline & $\begin{array}{l}\text { Quickly establish a short-term foundational ICT infrastructure for real-time 2-way } \\
\text { communication and data transmission (eg, a very small aperture terminal satellite) with } \\
\text { a consistent power supply (eg, solar panel batteries, generators) and procedures for } \\
\text { managing disruptions in connectivity due to overloaded bandwidth; and }\end{array}$ \\
\hline & $\begin{array}{l}\text { Identify low-resource ICT tools to optimize management of case data from remote } \\
\text { areas, such as short-term installation of satellite telephones or applications to transfer } \\
\text { case data on mobile devices using existing cellular networks rather than satellite } \\
\text { technology. }\end{array}$ \\
\hline
\end{tabular}


Table 1. (Continued)

\begin{tabular}{|c|c|}
\hline \multirow[t]{3}{*}{ Lesson Learned } & Practical Recommendations \\
\hline & $\begin{array}{l}\text { - Ensure continued availability of ICT specialists throughout the outbreak period to maintain } \\
\text { telecommunication equipment and systems; and }\end{array}$ \\
\hline & $\begin{array}{l}\text { - Conduct collaborative ICT monitoring visits with personnel from the district and provincial } \\
\text { health office to build ICT capacity through participatory training on routine maintenance } \\
\text { activities and techniques for resolving functionality issues. }\end{array}$ \\
\hline \multicolumn{2}{|r|}{ Post Outbreak } \\
\hline \multirow{9}{*}{$\begin{array}{l}\text { Preemptively plan outbreak } \\
\text { preparedness activities and } \\
\text { response strategies }\end{array}$} & $\begin{array}{l}\text { - Develop a preemptive emergency response plan, with detailed guidance on roles and } \\
\text { responsibilities at each level of the health pyramid and clear lines of reporting; }\end{array}$ \\
\hline & $\begin{array}{l}\text { - Identify a pool of experienced field epidemiologists and graduates of the Field Epidemiology } \\
\text { Training Program to serve on outbreak response surveillance teams and establish a mechanism } \\
\text { for rapid engagement (eg, memorandum of understanding between ministry of health and } \\
\text { current employers for short-term leave of absence); }\end{array}$ \\
\hline & $\begin{array}{l}\text { - Evaluate EVD case definitions and reporting tools used during the outbreak and modify as } \\
\text { needed to improve case detection and reporting in the post-outbreak period; }\end{array}$ \\
\hline & $\begin{array}{l}\text { - At the national level, provide a supportive infrastructure for case detection and reporting at } \\
\text { lower levels: }\end{array}$ \\
\hline & $\begin{array}{l}\text { Incorporate community, district, and provincial level training into the national plan for } \\
\text { building capacity in Integrated Disease Surveillance and Response; }\end{array}$ \\
\hline & $\begin{array}{l}\text { Convene annual meetings of surveillance partners and health workers in each district to } \\
\text { review routine and emergency reporting procedures, clarify roles, and identify the } \\
\text { resources available to scale-up surveillance activities during emergencies; and }\end{array}$ \\
\hline & $\begin{array}{l}\text { Develop a training and dissemination plan to ensure that updated EVD guidance is } \\
\text { available and well understood at every level of the health period. }\end{array}$ \\
\hline & $\begin{array}{l}\text { - Develop a formal emergency telecommunications plan for outbreak response. The plan should } \\
\text { include responsive strategies for overcoming anticipated ICT challenges, such as lack of } \\
\text { network coverage, inconsistent power supply, and problems maintaining ICT equipment; and }\end{array}$ \\
\hline & $\begin{array}{l}\text { - Proactively plan for accessibility and communication constraints by establishing an inventory } \\
\text { of satellite phones and internet modems for rapid deployment during outbreaks. If this is not } \\
\text { financially feasible, the ministry of health should identify partners who own the targeted } \\
\text { equipment and establish advance agreements to take temporary ownership during outbreak } \\
\text { responses. }\end{array}$ \\
\hline
\end{tabular}

single chain of transmission. The index case was found to have direct zoonotic exposure through contact with the carcass of a wild boar or nonhuman primate on March 15, 2017, followed by onset of symptoms on March 27, 2017. All subsequent cases resulted from human-to-human transmission. ${ }^{2}$ The investigative activities further revealed contextual factors that contributed to the 46-day delay between the index case's symptom onset and the official outbreak declaration on May 12, 2017, including insufficient knowledge of EVD case definitions at the health center and among community health workers, lack of community-based surveillance systems and tools, and the use of traditional healers for first-line care and treatment.

\section{LESSONS LEARNED}

Drawing on the surveillance team's experience in conducting outbreak response activities in Likati, we describe 6 critical lessons learned and offer practical recommendations to improve case detection, epidemiologic investigation, and the supportive information and communication technology infrastructure during zoonotic disease outbreaks in rural DRC and other resource-limited rural settings (Table 1).

\section{Assess and Adapt Case Definitions and Reporting Tools to the Outbreak Context}

At the outbreak onset, the surveillance team reviewed and updated case definitions and reporting tools (last updated in 2015) to facilitate effective case detection and management. The standard EVD case definition was broadened for community use to improve ascertainment of all illness and deaths that were potentially attributable to EVD and warranted further investigation. ${ }^{22}$ More detailed criteria were developed for facility-based health workers and the surveillance team to assess and classify alerts and suspected cases as probable, confirmed, or non-cases. Reporting tools 
were updated to improve the quality of case and contact data. This included registries and forms for case notification and investigation, contact tracing and monitoring, patient monitoring, and alert investigation. To reinforce accuracy and standardization, the surveillance team trained health workers at the facility and community level on the modified case definitions and reporting tools, monitored daily for correct usage, and provided corrective guidance as needed.

\section{Rapidly Deploy a Community Alert System Using Context-Appropriate Technology}

A well-publicized, low-resource community alert system can enhance timely and widespread detection of suspected cases in resource-limited areas. The surveillance team quickly identified the need for community-initiated alerts and established a simple system for use with basic (voice and SMS only) mobile phones, providing the following advantages: (1) they were capable of rapid deployment, (2) they required minimal resources and financial support, and (3) they used appropriate technology for Likati's resource-limited setting (Figure 2). The system proved to be an effective and well-used tool for rapid identification of potential cases and was cited by WHO as a critical factor for improved early detection of suspected cases. ${ }^{23}$ However, the Likati model may not be the most effective strategy for outbreaks that are larger in scope or situated in areas with better information and communication technology capacity. A situational analysis is required during each outbreak to assess if there are other, more contextually appropriate mechanisms for community members to quickly and inexpensively communicate alerts (eg, call centers).

\section{Build Local Capacity for Case Detection and Reporting}

Effective surveillance and rapid detection of emerging health threats requires an adequately trained public health workforce capable of identifying, investigating, and reporting essential information about public health threats. ${ }^{24}$ During the Likati outbreak, delayed detection and reporting resulted in a 46-day period between the date of symptom onset for the index case and the notification from provincial health authorities to the ministry of health of a potential EVD outbreak. Subsequent investigation showed that detection was hindered by the use of traditional healers as first-line health providers, a challenge that was also well-documented in the 2014-2016 EVD outbreak in West Africa. ${ }^{25}$ Case detection and reporting can be further delayed by community health workers' insufficient knowledge of EVD signs and symptoms and poor comprehension of EVD case definitions. By engaging community health workers in the surveillance process through participatory training and direct supervision from local health authorities, the timeliness of both disease detection and reporting is improved. ${ }^{17,26}$

\section{Develop Context-Specific Plan for Outbreak Data Collection, Management, and Use}

Procedures for managing case and contact data should be well documented to improve timely and accurate data sharing among contact tracers, supervisors, and the surveillance team. ${ }^{21,27}$ To understand the local environment and develop context-appropriate outbreak data management procedures, the surveillance team rapidly assessed the existing data management systems and information and communication technology infrastructure in Likati district. This included an assessment of data management processes and data flow from the Likati district health office to the Bas-Uéle provincial health office and to the ministry of health in Kinshasa. Specifically, the team reviewed how the current information system managed Ebola case investigation, case reporting, case management, contact tracing, contact follow-up, laboratory testing, laboratory results, daily situation reports, and contact mapping, then developed responsive strategies for improving outbreak data management. For example, community health workers lacked the technology to collect global positioning system coordinates at the homes of case contacts or places they visited, which is important for daily contact tracing and prompt management of potential cases. ${ }^{28}$ Therefore, a team was sent to the field to collect geolocation information via an Android-based application.

The surveillance team further improved management and use of outbreak data by implementing quality assurance procedures and promoting data-driven decision making. They established procedures to review data received for accuracy and completeness, returning to the source for data validation as needed. For example, when critically important data were identified as missing from case notification forms, a member of the surveillance team traveled to the location where the form originated to obtain the missing information. Furthermore, the team established daily meetings to review outbreak data, monitor progress, evaluate effectiveness, identify problems, plan or modify activities, allocate resources or staff, and identify epidemiologic trends. For example, data on the geographical distribution of cases and contacts were used to determine where to send essential equipment, such as satellite telephones, to rapidly report suspected cases and target community awareness campaigns.

\section{Strengthen Operational Support for Essential Communication and Information-Sharing Networks}

As part of the rapid assessment of the information and communication technology infrastructure available for outbreak response activities, the surveillance team assessed availability and functionality of information and communication technology networks and equipment, including computing hardware, software, and technical support systems in the outbreak epicenter. The assessment identified inadequate functionality of existing infrastructure at the 
district health office-specifically, damaged solar system kit or batteries, lack of electricity, no staff trained to resolve connectivity issues, and lack of vendor support to assist with maintenance of very small aperture terminal (VSAT) satellites, which are used for 2-way communication. Although 2 generators were installed to provide power to the district health office, lack of fuel remained a problem. The absence of a suitable system to automatically manage internet access led to disruptions in connectivity due to overloaded bandwidth, which had to be resolved by limiting the number of users at any given time and regularly changing the wifi encryption key. Two major national telecommunications networks (Vodacom and Orange) were available in Likati; however, they were slow and unstable and covered only 4 of the 11 health areas.

In response to identified constraints, the surveillance team purchased 2 satellite phones to facilitate communication and reporting of suspect cases and contact tracing information between the surveillance team and health areas without network coverage. Solar panel kits were also purchased and installed in remote health areas to charge mobile and satellite phones. Additionally, the surveillance team advised on information and communication technology resource management, helped troubleshoot functionality issues, and assisted outbreak partners, laboratory staff, and local health workers with hardware and software issues.

\section{Conclusions and Recommendations}

The public declaration of the 2017 Likati EVD outbreak came 46 days after the index case became symptomatic and 19 days after the first patient reported to a health center with Ebola-like symptoms. ${ }^{2}$ This delay in detection and reporting reveals possible weaknesses in the existing surveillance system for epidemic-prone diseases. In the Global Health Security Agenda, improving real-time surveillance and reporting of epidemic-prone diseases is a critical strategy for rapidly detecting and responding to public health threats. ${ }^{10}$ In areas such as Likati, where there is an elevated risk of exposure and transmission of zoonotic diseases, a well-functioning system for real-time surveillance and reporting serves as a critical early warning system and provides essential information for assessing the scale and distribution of a potential outbreak. However, this will require significant investment in building public health workforce capacity and healthcare infrastructure. The lessons learned during the Likati outbreak provide insight into interventions for improving outbreak response in the DRC and other rural resource-limited settings and can be used to build foundational surveillance capacity, in alignment with the Global Health Security Agenda objectives, for real-time surveillance and reporting. Our recommendations are:

- Strengthen EVD surveillance guidelines. Assess existing EVD surveillance guidelines, case definitions, and reporting tools targeted at community health workers and staff at each level of the health system; modify, as needed, to improve comprehension and ensure that they are properly applied for accurate and timely EVD case detection and reporting.

- Build health worker capacity for case detection and reporting. Provide participatory training and supportive supervision to improve comprehension and application of EVD surveillance guidelines and tools at the community and facility levels. Promote sustainability and efficiency by integrating training on EVD surveillance into existing national Integrated Disease Surveillance and Response training.

- Identify mechanisms to rapidly deploy a community alert system. Promote timely and widespread detection of suspected cases by establishing a simple, lowcost, easily accessible, community alert system that functions effectively in remote low-resource areas.

- Develop procedures and tools for improved outbreak data collection, management, and use. Ensure accuracy and completeness of contact data by developing processes and tools for systematic management of case data from point of identification to final classification, including integration of laboratory and clinical data, end-to-end contact tracing, timely and accurate reporting and feedback mechanisms at all levels, and automated data management and reports.

- Establish telecommunication protocols for low-resource settings. Ensure foundational information and communication technology infrastructure for routine surveillance that can be scaled up during outbreak response, by identifying critical equipment for realtime, 2-way communication and data sharing and proactive strategies for overcoming anticipated information and communication technology challenges, such as lack of network coverage, inconsistent power supply, and problems maintaining communications equipment.

\section{REFERENCES}

1. Communication speciale de son excellence monsier le ministre de la santé publique en rapport avec la situation épidémiologique du pays. [Special communication from His Excellence the Minister of Public Health in reference to the national epidemiological situation]. 2017. https://reliefweb.int/sites/ reliefweb.int/files/resources/20170511-communication-de-semle-ministre-de-la-sante\%CC $\% 81$-sur-situation-e\%CC\%81p..._0. pdf. Accessed December 5, 2019.

2. Nsio J, Kapetshi J, Makiala S, et al. 2017 outbreak of Ebola virus disease in northern Democratic Republic of Congo. J Infect Dis 2019. DOI: 10.1093/infdis/jiz107.

3. World Health Organization. Ebola Virus Disease, Democratic Republic of Congo. External Situation Report 60. 2019.https:// 
reliefweb.int/sites/reliefweb.int/files/resources/SITREP_EVD_ DRC_20190922-eng.pdf. Accessed September 24, 2019.

4. Ministry of Health, Democratic Republic of Congo. National Plan for the Response to the Ebola Virus Disease Epidemic in North Kivu Province. 2018. https://www.who.int/emergencies/ crises/cod/DRC-ebola-disease-outbreak-response-plan-10august 2018-1612-EN.pdf. Accessed May 15, 2019.

5. Rosello A, Mossoko M, Flasche S, et al. Ebola virus disease in the Democratic Republic of the Congo, 1976-2014. Elife 2015;4:e09015.

6. Maganga GD, Kapetshi J, Berthet N, et al. Ebola virus disease in the Democratic Republic of Congo. N Engl J Med 2014;371(22):2083-2091.

7. Ministere de la Santé Publique Secrétariat General. Rapport Annuel d'Activités de la Zone de Santé de Likati [Minister of Public Health Annual Report for Likati Health Zone, MoH]. 2017.

8. Plan National de Riposte à l'épidémie de la maladie à virus Ébola dans la zone de santé de Likati en province du basUélé MNCC. [National Ebola Response Plan in Likati Health Zone, Bas-Uele Province.] 2017.

9. Katz R, Sorrell EM, Kornblet SA, Fischer JE. Global Health Security Agenda and the International Health Regulations: moving forward. Biosecur Bioterror 2014;12(5):231-238.

10. Global Health Security Agenda. Action packages. 2019. https://www.ghsagenda.org/packages. Accessed August 18, 2019.

11. Suthar AB, Allen LG, Cifuentes S, Dye C, Nagata JM. Lessons learnt from implementation of the International Health Regulations: a systematic review. Bull World Health Organ 2018;96(2):110-121E.

12. Pigott DM, Deshpande A, Letourneau I, et al. Local, national, and regional viral haemorrhagic fever pandemic potential in Africa: a multistage analysis. Lancet 2017;390(10113):26622672.

13. Coltart CE, Lindsey B, Ghinai I, Johnson AM, Heymann DL. The Ebola outbreak, 2013-2016: old lessons for new epidemics. Philos Trans R Soc Lond B Biol Sci 2017;372(1721).

14. Moore M, Gelfeld B, Okunogbe A, Paul C. Identifying Future Disease Hot Spots: Infectious Disease Vulnerability Index. Santa Monica, CA: RAND Corporation; 2016.

15. Allen T, Murray KA, Zambrana-Torrelio C, et al. Global hotspots and correlates of emerging zoonotic diseases. Nat Commun 2017;8(1):1124.

16. Alexander KA, Sanderson CE, Marathe M, et al. What factors might have led to the emergence of Ebola in West Africa? PLoS Negl Trop Dis 2015;9(6):e0003652.

17. Stolka KB, Ngoyi BF, Grimes KEL, et al. Assessing the surveillance system for priority zoonotic diseases in the De- mocratic Republic of the Congo, 2017. Health Secur 2018; 16(Suppl):S44-S53.

18. Grard G, Biek R, Tamfum JJ, et al. Emergence of divergent Zaire Ebola virus strains in Democratic Republic of the Congo in 2007 and 2008. J Infect Dis 2011;204(Suppl 3):S776-S784.

19. Kantele A, Chickering K, Vapalahti O, Rimoin AW. Emerging diseases - the monkeypox epidemic in the Democratic Republic of the Congo. Clin Microbiol Infect 2016; 22(8):658-659.

20. Fenollar F, Mediannikov O. Emerging infectious diseases in Africa in the 21st century. New Microbes New Infect 2018;26: S10-S18.

21. Schafer IJ, Knudsen E, McNamara LA, Agnihotri S, Rollin PE, Islam A. The Epi Info Viral Hemorrhagic Fever (VHF) application: a resource for outbreak data management and contact tracing in the 2014-2016 West Africa Ebola epidemic. J Infect Dis 2016;214(Suppl 3):S122-S136.

22. Hsu CH, Champaloux SW, Keita S, et al. Sensitivity and specificity of suspected case definition used during West Africa Ebola epidemic. Emerg Infect Dis 2018;24(1):9-14.

23. World Health Organization. New technology allows for rapid diagnosis of Ebola in the Democratic Republic of the Congo. 2017. http://who.int/emergencies/ebola-DRC-2017/ articles/rapid-diagnosis/en/ Accessed September 23, 2017.

24. Angulo FJ, Cassell CH, Tappero JW, Bunnell RE. Progress and opportunities for strengthening global health security. Emerg Infect Dis 2017;23(13):S1-S4.

25. Vandi MA, van Griensven J, Chan AK, et al. Ebola and community health worker services in Kenema District, Sierra Leone: please mind the gap! Public Health Action 2017; 7(Suppl 1):S55-S61.

26. Alexander KA, Sanderson CE, Marathe M, et al. What factors might have led to the emergence of Ebola in West Africa? PLOS Negl Trop Dis 2015Apr;9(6).

27. Owada K, Eckmanns T, Kamara KB, Olu OO. Epidemiological data management during an outbreak of Ebola virus disease: key issues and observations from Sierra Leone. Front Public Health 2016;4:163.

28. Tom-Aba D, Olaleye A, Olayinka AT, et al. Innovative technological approach to Ebola virus disease outbreak response in Nigeria using the Open Data Kit and Form Hub Technology. PLoS One 2015;10(6):e0131000.

Address correspondence to: Jennifer J. Hemingway-Foday, MPH, MSW RTI International Research Triangle Park, NC

Email: hemingway@rti.org 